\title{
Kemik oluşturan selim tümörler
}

\author{
Bone-forming benign tumors
}

\author{
Seyit Ali Gümüştaş ${ }^{1}$, Önder Ofluoğlu² \\ ${ }^{1}$ Adıyaman Üniversitesi Eğitim ve Araştırma Hastanesi, Ortopedi ve Travmatoloji Anabilim Dalı, Adıyaman \\ ${ }^{2}$ Bahçeşehir Universitesi Tıp Fakültesi, Ortopedi ve Travmatoloji Anabilim Dalı, İstanbul
}

Kemik oluşturan, osteoblastik, tümörler olan osteom, osteoid osteom ve osteoblastom ağırlıklı olarak lamellar yapısı ile iyi farklılaşmış olgun kemik dokusu oluşturan ve çok yavaş büyüme gösteren iyi huylu lezyonlardır. Benign kemik oluşturan tümörlerin tanısı klinik ve radyolojik bulguların ilişkisi ile birlikte bu tümörlerin histopatolojik özelliklerine dayalıdır. Bu lezyonlar farklı klinik tablolara neden olabilseler de görüntüleme özellikleri genellikle karakteristiktir ve belirli bir tanı olabileceğini düşündürmektedir. Bununla birlikte her üç lezyonda başka bir kemik üreten lezyon olan osteosarkom ayırıcı tanıda göz önünde bulundurulmalıdır. Benign osteoblastik tümörlerden osteom sıklıkla paranazal sinüslerin ve kraniyumun kemik yüzeyinden kaynaklanan iyi sınırlı ve homojen bir lezyondur. Lezyon genellikle tesadüfen saptanır ve yerleşim yerine ve büyüklüğüne göre sinüzit, baş ağrısı ve çift görme gibi belirtilere neden olabilir. Uzun kemik tutulumu şişlik veya lokal ağrı ile kendisini gösterebilir. Osteoid osteom genellikle genç hastalarda uzun kemiklerin diafizini etkileyen ağrılı bir lezyondur. Direkt grafide genellikle çevresinde yoğun skleroz olan küçük radyolusen nidus görülür. Osteoblastom sıklıkla omurga ve uzun kemikleri tutan, histopatolojik olarak osteoid osteoma benzeyen fakat agresif davranış gösterebilen daha nadir bir tümördür. Osteoblastom farklı klinik tablo ve radyolojik görünümle karşımıza çıkabilir. Bu derlemede iyi huylu kemik oluşturan tümörlerin klinik ve radyolojik özellikleri ile birlikte güncel tedavi yaklaşımları sunulmuştur.

Anahtar sözcükler: osteom; osteoid osteom; osteoblastom
The bone forming, osteoblastic, tumors including osteoma, osteoid osteoma, and osteoblastoma are slow growing benign lesions, forming well differentiated mature bone tissue with a structure of lamellar bone. The diagnosis of these tumors is based on histopathological features correlated with clinical and radiological findings. Although they may present different clinical circumstances, imaging features of these lesions are usually characteristic and suggest that there is a certain diagnosis. However, osteosarcoma, another osteoblastic but malignant tumor, should be considered in the differential diagnosis of all of the three lesions. Osteoma is a well-defined and homogeneous lesion, often caused by bone surface of the paranasal sinuses and the cranium. The lesion is usually detected incidentally and can cause symptoms such as sinusitis, headaches and diplopia depending on the size and the location. Long bone involvement can show itself with swelling or local pain. Osteoid osteoma is a painful lesion, usually affects long bone diaphysis in young patients. A small radiolucent nidus surrounding the dense sclerosis is seen in the direct radiograph. Osteoblastoma is a rare tumor, often holds the spine and long bones, histologically similar to osteoid osteoma but it has more aggressive behavior. Osteoblastoma may present as different clinical presentation and radiological appearance. In this review the clinical and radiological features of benign bone forming tumors and the current treatment modalities are presented.

Key words: osteoma; osteoma, osteoid; osteoblastoma
K emik üreten benign tümörler; osteom, osteoid osteom ve osteoblastom, sıklıkla genç erişkinlerde görülen, lamellar yapıda, iyi diferansiye, olgun kemik dokusu oluşturan ve yavaş büyüme gösteren lezyonlardır.

Bu lezyonların görüntüleme özellikleri genellikle karakteristiktir. Tanıda ilk başvurulması gereken görüntüleme yöntemi konvansiyonel radyografidir. Bilgisayarlı tomografi (BT) omurga ve pelvis gibi anatomik bölgelerdeki tümörlerin optimum değerlendirmesi için gereklidir. Manyetik rezonans (MR) özellikle lezyonun çevre yumuşak dokular ve nörovasküler yapılarla ilişkisini görüntülemede yardımcıdır.

Osteom sıklıkla paranazal sinüslerde ve kraniyumda, kemik yüzeyinden kaynaklanan iyi sınırlı, homojen ve yoğun kitle olarak karşımıza çıkar. Genellikle

- İletişim adresi: Doç. Dr. Önder Ofluoğlu, Medical Park Göztepe Hastanesi, E5 Üzeri 23 Nisan Sok. No: 17 Merdivenköy, Kadıköy, İstanbul Tel: 0533 - 6009543 e-posta: oofluoglu@gmail.com

- Geliș tarihi: 27 Eylül 2013 Kabul tarihi: 27 Eylül 2013 
asemptomatiktir ve yerleşim yeri ve boyutuna göre sinüzit, baş ağrısı ve görme bozuklukları gibi belirtiler sonrası rastlantısal olarak tespit edilir. Kraniyum dışı tutulum daha azdır. Uzun kemiklerde, parosteal osteosarkom, osteokondrom ve miyozitis ossifikans gibi lezyonlarla karışabilir. Eksizyonel biyopsi tedavi için yeterlidir ve eksizyon sonrası nüks genellikle beklenmez.

Osteoid osteom ve osteoblastom histolojik olarak benzer görünümde fakat boyutları, yerleşim yerleri ve klinik bulguları farklı olan lezyonlardır. Osteoid osteom genellikle uzun kemiklerin diyafiz bölgesinde intrakortikal yoğun sklerotik halka ile çevrili küçük radyolusen lezyon olarak görülür. Skleroz nedeniyle büyük görülse de boyutları nadiren $1,5 \mathrm{~cm}$ 'yi geçer. Nonsteroidlere yanıt veren gece ağrısı tipik klinik bulgusudur. Tedavide medikal, açık cerrahi ve perkütan yöntemler olmak üzere üç temel farklı yaklaşım mevcuttur.

Osteoblastom sıklıkla omurga ve uzun kemiklerin metafiz kısmını tutmaktadır. Benign histolojiye rağmen bazen agresif davranış gösterebilir. Nadiren de olsa malign dönüşüm bildirilmiştir. Genellikle bir kemik kapsülü tarafından çevrili, değişik miktarda kalsifikasyonlar içeren, sıklıkla ekspansil, yer yer radyolusen ve yer yer blastik karakterde bir lezyondur. Karakteristik semptom lokalize, geceleri artmayan ve nonsteroidlere yanıtı osteoid osteoma göre daha az olan künt bir ağrıdır. Tedavide intralezyonal küretaj ilk seçenektir, ancak nüks olgularda ya da ileri derecede agresif lezyonlarda, uygun lokalizasyonda ise rezeksiyon gerekli olabilir.

\section{OSTEOM}

Osteom benign, lamellar yapı ile birlikte iyi derecede farklılaşmış olgun kemik dokusundan oluşan, yavaş büyüyen bir lezyondur. ${ }^{[1]}$

Bu lezyonun gelişiminde çoğu araştırmacı travmanın önemli bir rol oynamadığını düşünmektedir. ${ }^{[2]}$ Ancak O'Connell ve arkadaşları ${ }^{[3]}$ kraniyum dışı üç osteom olgusunun ikisinin tekrarlayıcı lokal travma öyküsü ile ilişkili olduğunu bildirmiştir.

Lezyonlar genellikle soliter olup, Gardner sendromunda (anormal diş yapısı, deri nodülleri, osteomlar ve kolon polipleri) çoklu olarak karşımıza çıkar. ${ }^{[4]}$

Osteom sıklıkla kraniyofasyal kemikleri tutar. Kraniyum dışı primer osteomlar çok nadirdir. Uzun ve kısa tübüler kemiklerdeki lezyonlar parosteal osteomlar olarak bilinir. Parosteal lezyonların çapı çoğunlukla 1-4 santimdir. Küçük lezyonlar genellikle asemptomatiktir ve tesadüfi olarak tespit edilir. Parosteal osteomlar erken erişkinlikte ortaya çıkarlar. Her iki cinsiyet eşit düzeyde etkilenir. Osteomlar sapsız yuvarlak ya da oval tümörlerdir ve korteksin endosteal veya subperiosteal yüzeyinden kaynaklanırlar. Ekstra kraniyal tutulumda şişlik ve/veya lokal ağrı belirgin klinik özelliklerdir. Birçok hastada semptomlar aylar hatta yıllarca sürebilmektedir (Şekil 1). ${ }^{[5-8]}$

Radyografilerde tipik olarak keskin sınırlı yoğun sklerotik kitle olarak görünürler. Osteomlarda kortikal invazyon görülmez. BT tümörün kortikal kemikle ilişkisini net olarak gösterebilir. MR görüntüleme $T 1$ ve T2 sekanslarda, kortikal kemik ile uyumlu düşük sinyal yoğunluğu izlenir. Üç fazlı kemik sintigrafisinde, etkilenen ekstremitede kanlanma artışı yoktur. Geç görüntüleme normal kemik dokusuyla aynı düzeyde veya hafif artmış tutulum gösterir. ${ }^{[9,10]}$

Ayrıcı tanıda osteokondrom, miyozitis ossifikans veya parosteal osteosarkom göz önünde bulundurulmalıdır. Osteomu tanımlamada radyografideki temel özellikler düzgün sınırlı, iyi çevrelenmiş, homojen ve sklerotik görünümdür. Bunun aksine parosteal osteosarkom, periferde azalmış yoğunluk zonu gösterebilir ve osteoma göre daha az yoğun ve homojen görünümdedir. ${ }^{[11,12]}$

Makroskopik olarak lezyon sınırları matür, yoğun lamellar kemik tabakalarından oluşmaktadır. Tümörün iç kısmında kalın mozaik görünümlü, immatür, örgülü kemik mevcuttur. ${ }^{[13]}$ Histolojik olarak osteoid osteomdan merkezi vasküler nidusun yokluğu ile, osteoblastomdan sellüler osteoid stromanın yokluğu ile ve parosteal osteosarkomadan atipik hücre yokluğu ile ayırt edilebilir. ${ }^{[13]}$ Atipik klinik bulgular veya radyografik görünüm varlığında insizyonel biyopsi yapılmalıdır.

Standart cerrahi yaklaşım lezyonun eksizyonudur. ${ }^{[2,3,9]}$ Uzun kemiklerdeki kitlelerin eksizyonunu takiben nüks bildirilmemiştir. ${ }^{[13]}$

\section{OSTEOID OSTEOM}

Osteoid osteom selim kemik tümörlerinin \%12'sini oluşturan ve en sık femur ve tibiada yerleşim gösteren bir tümördür. Etrafını çevreleyen skleroz ve ödem nedeniyle daha büyük görülse de boyutları nadiren 1,5 cm'yi geçer. Sıklıkla yaşamın ikinci on yılının ilk yarısında olmak üzere genç erişkinleri etkiler. Kadınlara oranla erkeklerde üç kat daha sık bildirilmiştir. ${ }^{[14-17]}$

Klinik, radyolojik ve sintigrafik bulgulara göre tanı konulan osteoid osteomda laboratuvar sonuçları tipik olarak normaldir. ${ }^{[18]}$

Osteoid osteomlı hastalarda öncelikli klinik belirti, geceleri artan, uykuyu etkileyen ve nonsteroid antiinflamatuvar ilaç (NSAii) tedavisiyle azalan gece ağrısıdır. ${ }^{19]}$ Birçok hastada özellikle uzun süren ve tedavide gecikilen olgularda tutulan ekstremitede atrofi, ekleme yakın 

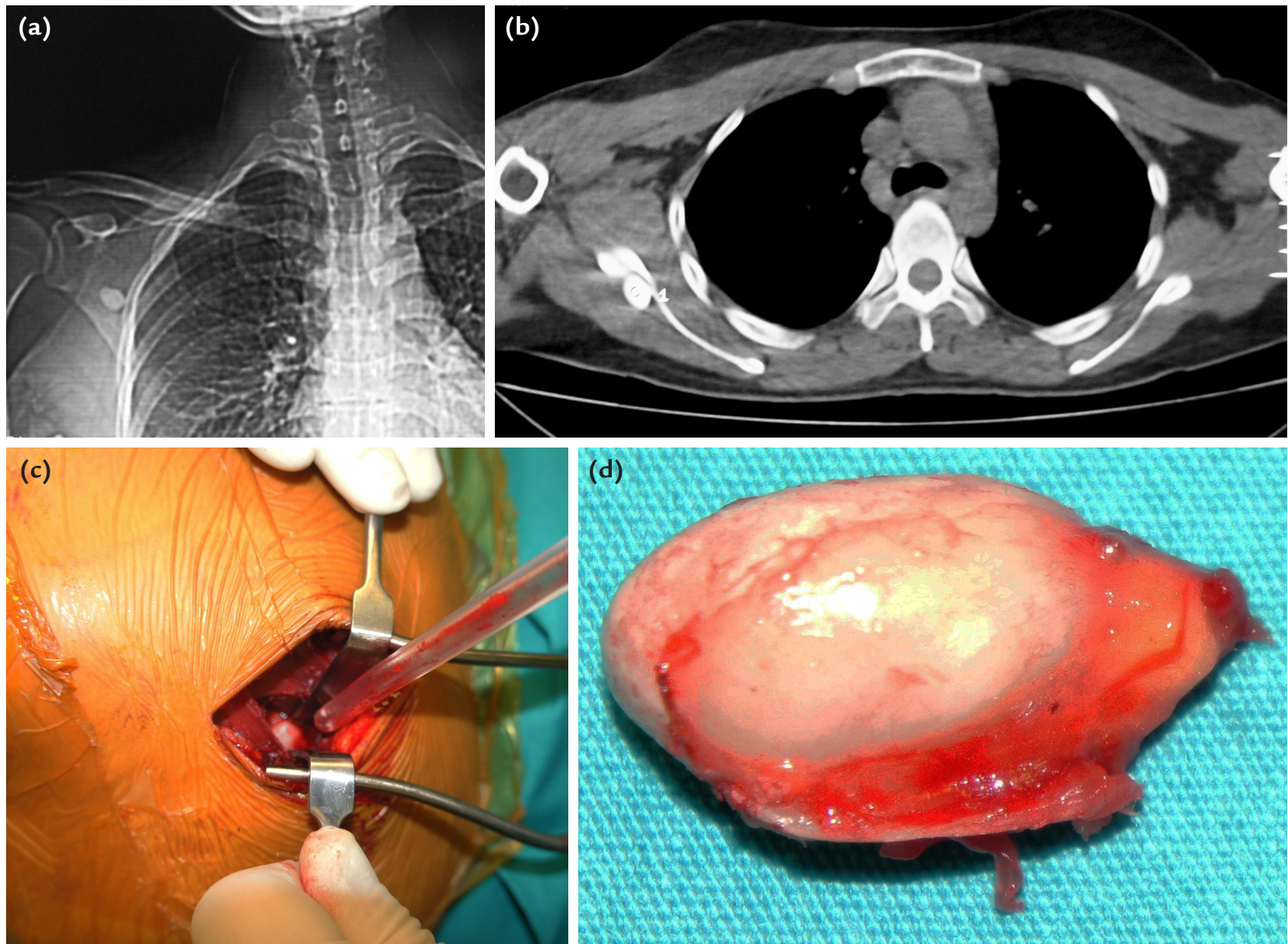

Şekil 1. Otuz iki yaşında kadın hastada skapula lokalizasyonlu, yoğun, yuvarlak, tümüyle sklerotik kitle: osteoma. Lezyon bilgisayarlı tomografik işaretleme sonrası minimal invaziv yöntemle eksize edilmiştir.

olgularda deformasyon ve artroz ve birçok olguda reaktif depresyon bulguları görülebilmektedir.

Klasik radyolojik görüntü; yoğun sklerotik halka ile çevrili küçük radyolusen lezyon "nidus” şeklindedir. Nidusu, etrafını çevreleyen skleroz ve periosteal reaksiyondan ayırmada ve lezyonun lokalizasyonunda BT vazgeçilmezdir. Sintigrafi özellikle radyografik olarak lezyonun belirlenemediği durumlarda ya da tanı güçlüğü arz eden olgularda kullanılabilir. MR, kortikal lezyonlarda çok yararlı değilken, özellikle metafizer veya eklem çevresi tutulumda eklem içi patolojilerin dışlanmasında yardımcıdır (Şekil 2). [20-23]

Osteoid osteomun merkezinde osteoblastlarla çerçeveli osteoid ve örgü kemikten oluşan bir nidus bulunmaktadır. Nidusu, kalınlaşmış kortikal veya trabeküler kemik ve gevşek fibrovasküler dokudan oluşan reaktif bir bölge çevreler. Şüpheli olgularda, özellikle Brodie absesi, stres kırığı, kondrobastoma ve osteoblastomdan ayırıcı tanısı yapılmalıdır. ${ }^{[19]}$
Osteoid osteom medikal veya cerrahi yöntemlerle tedavi edilmektedir. Aspirin veya diğer NSAiỉ'ler sıklıkla etkin ağrı kontrolü sağlar ancak uzun süreli tedavi, dirençli ağrı ve uykusuzluğa neden olan gece ağrıları veya gastrointestinal komplikasyonlar sebebiyle, sıklıkla sürdürülebilir değildir. Osteoid osteomun spontan iyileşmesi bildirilse de, total tedavi süresi ve uzun süre ilaç kullanım gereksinimine bağı gastrointestinal sorunlar nedeniyle, medikal tedavi genellikle tercih edilmemektedir. ${ }^{[19]}$

Osteoid osteom geleneksel olarak açık rezeksiyonla tedavi edilmekteydi. Hâlâ birçok merkez açık cerrahi rezeksiyonu uygulamaktadır. Farklı çalışmalarda hastaların \%88-100'ünde nüks olmaksızın tedavi sağlanabildiği bildirilmiştir. ${ }^{[24,25]}$ Ancak özellikle küçük, intrakortikal yerleşimli ya da pelvis omurga gibi bölgelerde, çeşitli lokalizasyon tekniklerine rağmen, operasyon esnasında lezyonun tespiti zor olduğundan; yetersiz cerrahi nedeniyle ikincil girişim uygulanması, fiksasyon 

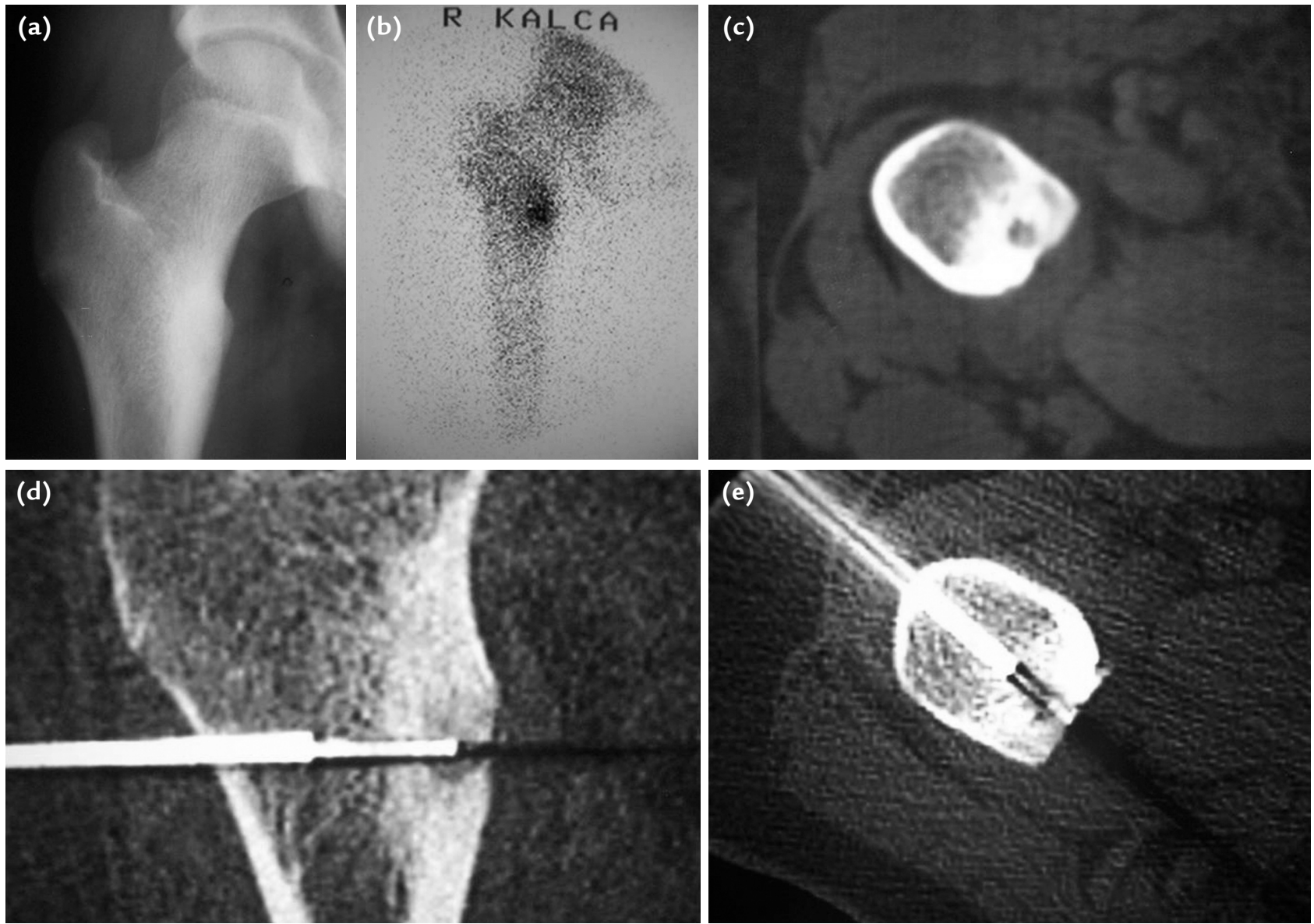

Şekil 2. Proksimal femur yerleşimli osteoid osteomada yoğun, reaktif skleroz; sintigrafide artmış aktivite ve bilgisayarlı tomografide tipik nidus görünümü. Lezyon indirekt lateral yaklaşım kullanılarak radyofrekans ablasyonla tedavi edilmiştir.

gereksinimi ve rehabilitasyon süresinin uzun olması, enfeksiyon, kozmetik gibi sorunlarla karşılaşılabilmektedir. Açık cerrahi girişim, nidusun nörovasküler yapılara 1-1,5 cm'den daha yakın olduğu yerleşim yerinde, histopatolojik tanının şüpheli olduğu ve iki kez ablasyon uygulanmasına rağmen semptomların devam ettiği olgularda tercih edilmektedir. ${ }^{[25-30]}$

BT veya floroskopi eşliğinde perkütan rezeksiyon, uygulanan bir diğer yöntem olup perkütan radyofrekans termoablasyon (PRT) ile karşılaştırıldığında daha uzun süreçtir ve uygulama sonrası daha yüksek morbidite oranına sahiptir. ${ }^{[25,31]}$

PRT, termal koagülasyon yoluyla lezyon içinde nekrozla ablasyona dayanan, cerrahi tedaviye alternatif minimal invaziv bir tekniktir. Son yıllarda osteoid osteom tedavisindeki en popüler yöntemdir. ${ }^{[16,34,35]}$

PRT tekniğinin klinik başarısı ilk kez Rosenthall ve arkadaşları tarafından açıklanmıştır. illk uygulamada \%76100 arasında başarı bildirilmektedir. ${ }^{[25,36,37]}$ Prosedür ortalama 40-60 dakika sürmekte ve işlem sonrası hastanede kalış süresi 3-24 saat arasında olmaktadır. ${ }^{[38]}$

PRT sonrası \%5-25 arasında nüks oranları bildirilmektedir ${ }^{[35,39,40]}$ ve bunlar sıklıkla ilk yedi ayda ortaya çıkar. ${ }^{[25]}$ Uygulama sonrası ağrının devam etmesi durumunda ilk akla gelmesi gereken, yetersiz lokalizasyon ya da ablasyona bağlı nüks veya kalan tümör daha düşük oranda ise komşu yumuşak dokuların irritasyonudur. ${ }^{[37]}$ Bir santimden büyük lezyonlarda, elektrodun farklı açılarda birden fazla uygulanması gerekmektedir. ${ }^{28]}$ Tekrarlayan osteoid osteomların PRT ile tedavisinde aynı şekilde yüksek başarı oranları (\%60-100) bildirilmiştir. ${ }^{[18,25,37,41,42]}$

PRT uygulamalarında en yaygın komplikasyon cilt yanığı olarak tespit edilmekle birlikte, sinir hasarı özellikle endişe vericidir ve bazı olgularda sinir hasarını önlemek için karşı korteks yoluyla giriş gerekli olabilir. ${ }^{[16,18,35,37,40]}$

Bu uygulamadaki bir diğer majör komplikasyon, dril giriş yerinde kırık gelişmesidir. ${ }^{[40]}$ Büyük ya da 

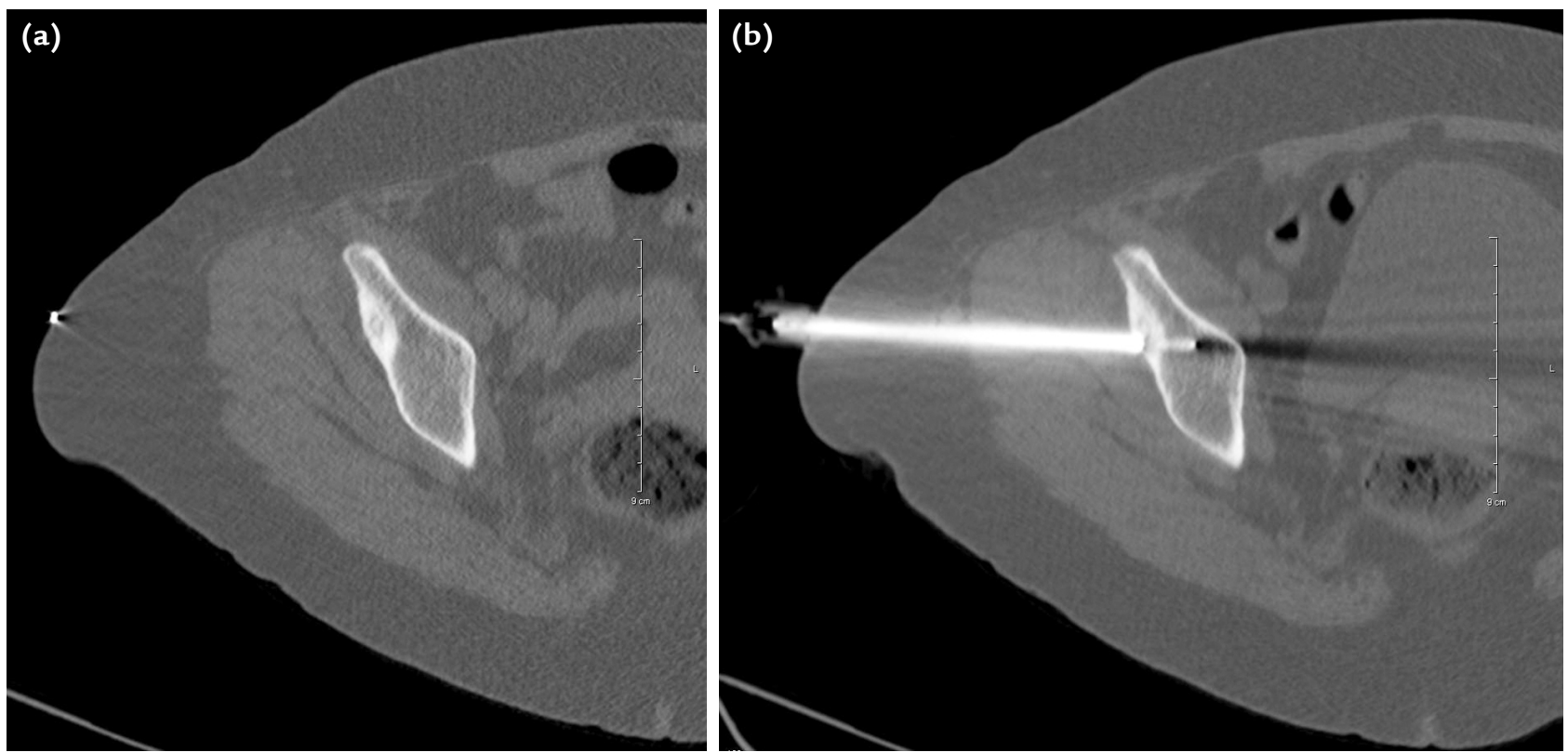

Şekil 3. Kırk sekiz yaşında kadın hastada, iliak kanatta, asetabuler çatıya yakın yerleşimli osteoid osteoma ve radyofrekans ablasyonla tedavisi.

birden fazla drilleme ve uygulama alanında geniş bir hücresel ablasyonun zayıflatıcı etkisi, kırık oluşma riskini arttırabilmektedir. ${ }^{[16,31]}$ Onarım sürecinde mekanik zayıflamalara yol açabileceğinden, özellikle proksimal femur gibi kırık açısından riskli bölgelerde 1-3 ay süreyle spor aktivitelerinin kısıtlanması önerilmektedir. ${ }^{[16,18,43]}$

Son beş yıl içinde, yaklaşık 50 civarında osteoid osteom ablasyonu uygulamamızdan; üç olgumuzda nüks, bir hastada ise ablasyonun altıncı haftasında sportif aktivite sırasında kırık ile karşılaştık. Böylece bizim serimizde başarı oranı primer uygulamada \%92 olarak izlenmiş̧tir (Şekil 3).

\section{OSTEOBLASTOM}

Osteoblastomlar tüm primer kemik tümörlerinin $\% 0,5-2$ 'sini ve benign kemik tümörlerinin ise sadece \%3'ünü oluştururlar. ${ }^{[44]}$ Osteoblastom iskeletin herhangi bir bölümünde görülebilir. En sık görülen bölgeler omurga ve uzun kemiklerdir. Tümör sıklıkla metafiz yerleşimi ile karşımıza çıkar fakat diyafız ve çok nadir olarak epifiz tutulumu da görülebilir. ${ }^{[44-46]}$

Osteoblastom her yaşta görülebilir fakat gençleri daha çok etkilemektedir. Tümörlerin \%80’i 30 yaştan önce görülür. Erkeklerde kadınlardan daha fazla görülür.

Tümörün lokalizasyonu ve büyüklüğüne göre semptom ve belirtiler değişken olmakla birlikte karakteristik semptom, lokalize, geceleri özellikle artış göstermeyen ve NSAil'lere osteoid osteom gibi iyi yanıt vermeyen künt bir ağrıdır. ${ }^{[47]}$

Radyografide osteoblastom bir kemik kapsülü tarafında sarılı ekspansil radyolusen lezyon olarak kendini gösterir. Lezyon değişken ölçülerde kalsifikasyon içerebilir. Osteoblastom, korteks yıkımı ve yumuşak doku yayılımı gibi malign tümörlerdekine benzer özellikler taşıyabilir. BT, tümör içerisinde küçük kalsifikasyonları saptayarak tanıya yardımcı olabilir, kortikal kemikteki lezyonun büyüklügüüü ve uzanımını gösterir ve ameliyatın planlanmasına yardımcı olur. Osteoblastom, sintigrafide belirgin tutulum gösterir. Sintigrafi, lezyonu lokalize etmekte ve çok odaklı lezyonları saptamakta yararlıdır fakat tümörün görüntüsü özgün değildir. Osteoblastomun MR görüntüleri özgün değildir. T1 ağırıklı görüntülerde düşük, T2 ağırlıklı görüntülerde yüksek sinyal görüntüsü verir. Bununla birlikte MR intramedüller ve ekstramedüller yayılımı görüntülemede yardımcı olur. ${ }^{[45-49]}$

Osteoblastomun patolojik özellikleri osteoid osteoma benzerdir. Her ikisi de osteoblast orijinli, kemik üreten lezyonlardır. Makroskopik olarak genelde lezyon kırmızıkahve renkli, bazen pembe renkte, kırılgan kumlu kıvamda ve hemorajik olarak görülür. Mikroskopik görüntüde, çevre kemik dokudan düzgün bir sınırla ayrılmış, gevşek fibrovasküler stroma içerinde anastomazlaşan düzensiz kemik trabekülleri mevcuttur. Trabeküller çevresinde tek sıra dizilmiş osteoblastlar ve arada osteoklast tipi dev hücreler dikkati çekmektedir. ${ }^{[50]}$ 

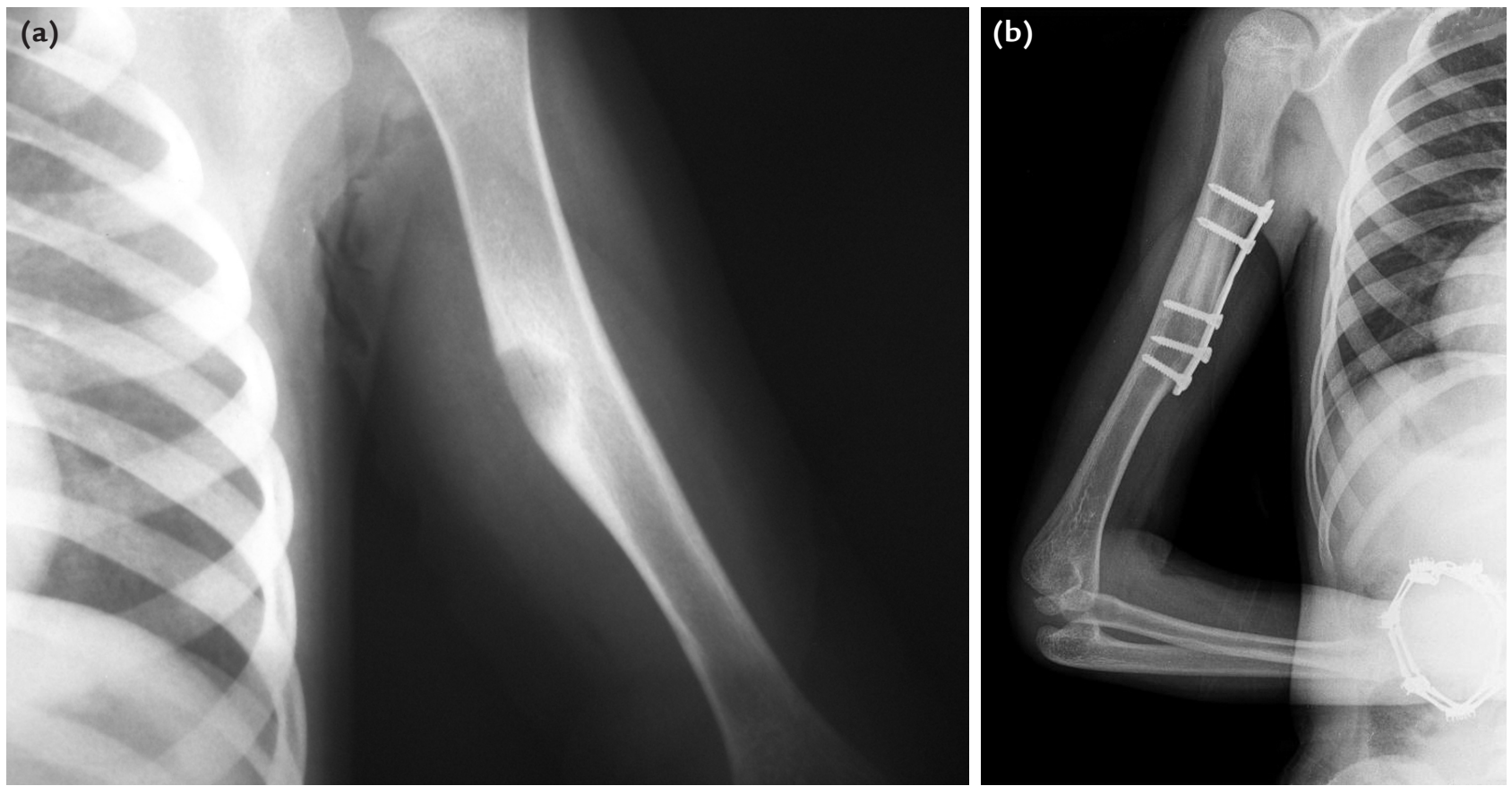

Şekil 4. Dört yaşında kız çocuğunda radyolojik olarak dev osteoid osteomaya benzeyen nüks osteoblastom. Lezyonun en-blok interkalar rezeksiyon sonrası oluşan defekt fibula allogrefti ile rekonstrükte edilmiştir.

Agresif osteoblastomlar sıradan osteoblastomlara göre klinik açıdan daha agresif seyirli, patolojik açıdan ise mitotik olarak daha aktiftir. Agresif osteoblastomun lokal nüks riski daha yüksek olmakla birlikte, literatürde malign transformasyonu bildirilmemiştir. Yine de bazı osteoblastomların low grade osteosarkom olabileceği tartışması sürmektedir.

Osteoblastomun tedavisinde total eksizyon gereklidir. Yüksek hızlı "burr" ve adjuvan uygulamalarla desteklenmiş "genişletilmiş intralezyonel küretaj" tercih edilmesi gereken yöntemlerdir (Şekil 4). En blok rezeksiyon kaburga, fibula ve distal ulna gibi bölgelerde uygulanabilir. ${ }^{[51,52]}$ Omurga lezyonlarında en blok rezeksiyon tercih edilmelidir. Anatomik lokalizasyonlar nedeniyle yetersiz rezeksiyon yapıldığında, lokal kontrolu sağlamak için bazı araştırmacılar radyoterapi önerse de, sekonder malignensi riskinin artacağı dikkate alınmalıdır.

Benign osteoblastomlar yaklaşık olarak \%10-20 nüks riskine sahiptir. ${ }^{[48,50,53]} \mathrm{Bu}$ nedenle hastaların yakın takibi gerekir. Nüksler, ameliyattan sonraki iki yıl içinde mikroskopik veya makroskopik tümör kalıntılarından gelişir. íki yıldan sonra nüks oldukça nadirdir.

\section{KAYNAKLAR}

1. Sadry F, Hessler C, Garcia J. The potential aggressiveness of sinus osteomas. A report of two cases. Skeletal Radiol 1988;17(6): 427-30.

2. Peyser AB, Makley JT, Callewart CC, Brackett B, Carter JR, Abdul-Karim FW. Osteoma of the long bones and the spine. A study of eleven patients and a review of the literature. J Bone Joint Surg Am 1996;78(8):1172-80.

3. O'Connell JX, Rosenthal DI, Mankin HJ, Rosenberg AE. Solitary osteoma of a long bone. J Bone Joint Surg 1993;75(12):1830-4.

4. Gardner EJ, Richards RC. Multiple cutaneous and subcutaneous lesions occurring simultaneously with hereditary polyposis and osteomatosis. Am J Hum Genet 1953;5(2):139-47.

5. Mirra JM, Picci P, Gold RH. Bone tumors: clinical, pathologic, and radiologic correlations. Philadelphia: Lea and Febiger, 1989: 226-48.

6. Baum PA, Nelson MC, Lack EE, Bogumill GP. Case report 560: Parosteal osteoma of tibia. Skeletal Radiol 1989;18(5):406-9.

7. Geschickter CF, Copeland MM. Parosteal osteoma of bone: a new entity. Ann Surg 1951;133(6):790-807.

8. Schajowicz F. Tumors and tumorlike lesions of bone: pathology, radiology and treatment. 2 nd ed. Berlin: SpringerVerlag; 1994. p.30-2, 52-6, 406-11.

9. Sundaram M, Falbo S, McDonald D, Janney C. Surface osteomas of the appendicular skeleton. AJR Am J Roentgenol 1996;167(6):1529-33

10. Lambiase RE, Levine SM, Terek RM, Wyman JJ. Long bone surface osteomas: imaging features that may help avoid unnecessary biopsies. AJR Am J Roentgenol 1998;171(3):775-8. 
11. Greenspan A. Orthopedic imaging: a practical approach, 4th ed. New York: Lippincott Williams \& Wilkins; 2004. p.571-5, 584-94.

12. Unni KK, Dahlin DC, Beabout JW, Ivins JC. Parosteal osteogenic sarcoma. Cancer 1976;37(5):2466-75.

13. Stern PJ, Lim EV, Krieg JK. Giant metacarpal osteoma. A case report. J Bone Joint Surg Am 1985;67(3):487-9.

14. Unni KK. Osteoid osteoma. In: Unni KK, Dahlin DC, editors. Dahlin's bone tumors. 5th ed. Philadelphia: LippincottRaven; 1996. p.121-30.

15. Greenspan A. Benign bone-forming lesions: osteoma, osteoid osteoma, and osteoblastoma. Clinical, imaging, pathologic, and differential considerations. Skeletal Radiol 1993;22(7):485-500.

16. Cantwell CP, O’Byrne J, Eustace S. Radiofrequency ablation of osteoid osteoma with cooled probes and impedancecontrol energy delivery. AJR Am J Roentgenol 2006;186(5 Suppl):S244-8.

17. Resnik D, Kyriakos M, Guerdon D. Tumors and tumor likes lesions of bone: Imaging and Pathology of specific lesions. In: Greenway Bone and Joint Imaging. 3rd ed. Elsevier Saunders; 2005. p.1121-98.

18. Rosenthal DI, Hornicek FJ, Torriani M, Gebhardt MC, Mankin HJ. Osteoid osteoma: percutaneous treatment with radiofrequency energy. Radiology 2003;229(1):171-5.

19. Motamedi D, Learch TJ, Ishimitsu DN, Motamedi K, Katz MD, Brien EW, Menendez L. Thermal ablation of osteoid osteoma: overview and step-by-step guide. Radiographics 2009;29(7):2127-41. CrossRef

20. Campanacci M, Ruggieri P, Gasbarrini A, Ferraro A, Campanacci L. Osteoid osteoma. Direct visual identification and intralesional excision of the nidus with minimal removal of bone. J Bone Joint Surg Br 1999;81(5):814-20.

21. Assoun J, Richardi G, Railhac JJ, Baunin C, Fajadet P, Giron J, Maquin P, Haddad J, Bonnevialle P. Osteoid osteoma: MR imaging versus CT. Radiology 1994;191(1):217-23.

22. Helms CA, Hattner RS, Vogler JB 3rd. Osteoid osteoma: radionuclide diagnosis. Radiology 1984;151(3):779-84.

23. Goldman AB, Schneider R, Pavlov H. Osteoid osteomas of the femoral neck: report of four cases evaluated with isotopic bone scanning, $\mathrm{CT}$, and MR imaging. Radiology 1993;186(1):227-32.

24. Cioni R, Armillotta N, Bargellini I, Zampa V, Cappelli C, Vagli P, Boni G, Marchetti S, Consoli V, Bartolozzi C. CT-guided radiofrequency ablation of osteoid osteoma: long-term results. Eur Radiol 2004;14(7):1203-8.

25. Cantwell CP, Obyrne J, Eustace S. Current trends in treatment of osteoid osteoma with an emphasis on radiofrequency ablation. Eur Radiol 2004;14(4):607-17.

26. Demiralp B, Yildiz C, Keskinbora M, Kose O, Basbozkurt M. Intraarticular osteoid osteoma of the hip; a challenging diagnosis. Medicine Science 2012;1(2):131-40.

27. Graham HK, Laverick MD, Cosgrove AP, Crone MD. Minimally invasive surgery for osteoid osteoma of the proximal femur. J Bone Joint Surg Br 1993;75(1):115-8.

28. Mahata KM, Keshava SK, Jacob KM. Osteoid osteoma of the femoral head treated by radiofrequency ablation: a case report. J Med Case Rep 2011;5:115. CrossRef

29. Aynaci O, Sener M, Aydin H, Gurcan O. Osteoid osteomas localized in the proximal femur. Acta Orthop Traumatol Turc 2001;35:95-8.
30. Efstathopoulos N, Sapkas G, Xypnitos FN, Lazarettos I, Korres D, Nikolaou VS. Recurrent intra-articular osteoid osteoma of the hip after radiofrequency ablation: a case report and review of the literature. Cases J 2009;2:6439. CrossRef

31. Sans N, Galy-Fourcade D, Assoun J, Jarlaud T, Chiavassa $H$, Bonnevialle $P$, Railhac N, Giron J, Morera-Maupomé $\mathrm{H}$, Railhac JJ. Osteoid osteoma: CT-guided percutaneous resection and follow-up in 38 patients. Radiology 1999;212(3):687-92.

32. Nehme AH, Bou Ghannam AG, Imad JP, Jabbour FC, Moucharafieh R, Wehbe J. Arthroscopic excision of intraarticular hip osteoid osteoma: a report of 2 cases. Case Rep Orthop 2012;2012:820501. CrossRef

33. Barnhard R, Raven EE. Arthroscopic removal of an osteoid osteoma of the acetabulum. Knee Surg Sports Traumatol Arthrosc 2011;19(9):1521-3. CrossRef

34. Barei DP, Moreau G, Scarborough MT, Neel MD. Percutaneous radiofrequency ablation of osteoid osteoma. Clin Orthop Relat Res 2000;(373):115-24.

35. Lindner NJ, Ozaki T, RoedI R, Gosheger G, Winkelmann W, Wörtler K. Percutaneous radiofrequency ablation in osteoid osteoma. J Bone Joint Surg Br 2001;83(3):391-6.

36. Papagelopoulos PJ, Mavrogenis AF, Kyriakopoulos CK, Benetos IS, Kelekis NL, Andreou J, Soucacos PN. Radiofrequency ablation of intra-articular osteoid osteoma of the hip. J Int Med Res 2006;34(5):537-44.

37. Vanderschueren GM, Taminiau AH, Obermann WR, Bloem JL. Osteoid osteoma: clinical results with thermocoagulation. Radiology 2002;224(1):82-6.

38. Rosenthal DI, Hornicek FJ, Wolfe MW, Jennings LC, Gebhardt MC, Mankin HJ. Decreasing length of hospital stay in treatment of osteoid osteoma. Clin Orthop Relat Res 1999;(361):186-91.

39. Ghanem I, Collet LM, Kharrat K, Samaha E, Deramon H, Mertl P, Dagher F. Percutaneous radiofrequency coagulation of osteoid osteoma in children and adolescents. J Pediatr Orthop B 2003;12(4):244-52.

40. Jankharia B, Burute N. Percutaneous radiofrequency ablation for osteoid osteoma: How we do it. Indian J Radiol Imaging 2009;19(1):36-42. CrossRef

41. Pinto $\mathrm{CH}$, Taminiau $\mathrm{AH}$, Vanderschueren $\mathrm{GM}$, Hogendoorn PC, Bloem JL, Obermann WR. Technical considerations in CT-guided radiofrequency thermal ablation of osteoid osteoma: tricks of the trade. AJR Am J Roentgenol 2002;179(6):1633-42.

42. Rosenthal DI. Percutaneous radiofrequency treatment of osteoid osteomas. Semin Musculoskelet Radiol 1997;1(2):265-72.

43. Rosenthal DI, Hornicek FJ, Wolfe MW, Jennings LC, Gebhardt MC, Mankin HJ. Percutaneous radiofrequency coagulation of osteoid osteoma compared with operative treatment. J Bone Joint Surg Am 1998;80(6):815-21.

44. Berry M, Mankin H, Gebhardt M, and Rosenberg A, Hornicek F. Osteoblastoma: a 30-year study of 99 cases. J Surg Oncol 2008; 98(3):179-83. CrossRef

45. Lucas DR, Unni KK, McLeod RA, O'Connor MI, Sim FH. Osteoblastoma: clinicopathologic study of 306 cases. Hum Pathol 1994;25(2):117-34.

46. Dorfman HD, Czerniak B. Benign osteoblastic tumors. In: Bone Tumors. 1st ed. St Louis: Mosby, 1998. p.85-127.

47. Kroon HM, Schurmans J. Osteoblastoma: clinical and radiologic findings in 98 new cases. Radiology 1990;175(3):783-90. 
48. Resnick D. Tumors and tumor-like lesions of bone: imaging and pathology of specific lesions. In: Resnick D, editor. Diagnosis of Bone and Joint Disorders. 3rd ed. Philadelphia: WB Saunders, 1995. p.3786-96.

49. Chakrapani SD, Grim K, Kaimaktchiev V, Anderson JC. Osteoblastoma of the spine with discordant magnetic resonance imaging and computed tomography imaging features in a child. Spine (Phila Pa 1976) 2008;33(25):E96870. CrossRef

50. Frassica FS, Waltrip RL, Sponseller PD, McCarthy EF Jr. Clinicopathologic features and treatment of osteoid osteoma and osteoblastoma in children and adolescents. Orthop Clin North Am 1996;27(3):559-74.
51. Arkader A, Dormans JP. Osteoblastoma in the skeletally immature. J Pediatr Orthop 2008;28(5):555-60. CrossRef

52. Ferracini R, Masterson EL, Bell RS, Wunder JS. Distal ulnar tumours. Results of management by en bloc resection in nine patients and review of the literature. J Hand Surg $\mathrm{Br}$ 1998;23(4):517-21.

53. Jackson RP. Recurrent osteoblastoma: a review. Clin Orthop Relat Res 1978;(131):229-33. 